\title{
Exotismo arqueológico en la literatura de fines del siglo XIX: 1880-1895
}

LILY LITVAK

Universidad de Texas

«Hay dos tipos de exotismo, el primero da el gusto por el desplazamiento en el espacio, la atracción por América, por las mujeres amarillas o verdes. Pero hay un placer más refinado, una corrupción más suprema, es el exotismo a través del tiempo" ${ }^{1}$. Esta cita es de Théophile Gautier, y se refería el autor de Le Roman de la Momie ${ }^{2}$ a una de las modas más populares del siglo XIX, el exotismo arqueológico. El tiempo también tiene sus lejanías, en el pasado, naturalmente, pues el futuro es para los hombres de acción, y no lo eran los estetas finiseculares. Así, a medida que avanzaba el siglo, se popularizaron los temas relacionados con las culturas de la Antigüedad.

El exotismo arqueológico podía satisfacer varios ideales a la vez. Desde luego, tenemos el tema ruinista, tan caro a aquella época, que veía en él una percepción dolorosa del declinar de las civilizaciones. Pero no es éste el tema que nos atañe ahora, sino, por el contrario, el exotismo que intenta revivir el pasado en todo su colorido y movimiento.

1 Théophile Gautier, Loin de Paris, París, Carpentier, 1881, 124.

2 Le Roman de la momie, Paris, Hachette, 1856. 
Este exotismo, por una parte, justificaba las audacias imaginativas, el deseo de extravagancia, de lo raro y pintoresco. Por otra, cumplía con ciertos requisitos de exactitud y erudición. Se podía a través de él conocer costumbres extrañas, distintas de la realidad contemporánea, y a la vez abordar ciertos aspectos de la vida cotidiana que adquirían, en aquel contexto, el aspecto de costumbres exóticas, aunque fuesen familiares.

La popularidad de estos temas era promovida por las investigaciones arqueológicas y los estudios eruditos. Entonces se revisan «Los perfumes de la antigüedad» en La Ilustración de España ${ }^{3}$, se detalla el Museo Bulacq en El Cairo ${ }^{4}$, y se familiariza el público español con las excavaciones del alto Nilo ${ }^{5}$. Pèl \& Ploma, revista catalana, discute lo «Arxiprimitiu» ${ }^{6}$. Esa afición promovió el ciclo de conferencias organizadas por José Ramón Mélida sobre el arte de la antigüedad, donde se discutió el arte tebano, el arcaísmo griego, el arte micénico, el naturalismo romano ${ }^{7}$. En sus artículos, este incansable trabajador de la arqueología deseaba dar a conocer al público español el valor artístico de los vasos griegos y etruscos del Museo Arqueológico Nacional ${ }^{8}$.

Simultáneamente, en la península, varios descubrimientos alentaron la popularidad de estos temas. Entre ellos, los hallazgos del Cerro de los Santos, cuya discusión data de 1860, luego prolongada en los años setenta y luego a fines de siglo. Este episodio puede ser conocido para los estudiosos de la literatura española, pues figura como tema en $\mathbf{L a}$ Voluntad de Azorín. Lo que no se conoce es toda la polémica científica y artística suscitada alrededor de esas estatuas. En la novela de Azorín

3 Eugenio Rumel, «Los perfumes de la antigüiedad», La Ilustración de España, IV, N. ${ }^{\circ} 40$ (22 octubre, 1887), 318-19.

4 La Ilustración Artística, VII, N. ${ }^{\circ} 333(14$ mayo 1888), 166-7. Véase también «La odisea de un faraón», La Ilustración Española y Americana, XXVI, N. ${ }^{\circ} 32$ (30 agosto 1882), 126-7.

5 Ibíd; XLIII, N. ${ }^{\circ} 7(22$ febrero 1899),. 195-6.

6 Saktawara, «Arxiprimitiu», Pel \& Ploma, N. 78 (1901), 51-57.

7 Estas conferencias se impartían en el Museo Arqueológico. Véase la reseña en la Revista de Archivos, Bibliotecas y Museos, 3. ${ }^{a}$ época, V (11 noviembre 1901), 65-72.

8 José Ramón Mélida, «Sobre los vasos griegos, etruscos e italogriegos del Museo Arqueológico Nacional», La Ilustración Española y Americana, XXVI, N. ${ }^{\circ} 31$ (2 agosto 1882), 102-6. También de Mélida véase «La colección de bronces antiguos de don Antonio Vives», Revista de Archivos, Bibliotecas y Museos, IV, (enero 1900), 27-30. 
aparece el padre Carlos Lasalde, persona que efectivamente existió, aficionado a la arqueología, que escribió estudios sobre las estatuas asignándoles un origen anterromano y suponiéndolas bastetanas ${ }^{9}$. Numancia fue otro de los sitios arqueológicos donde se continuaron los trabajos arqueológicos que se habían abandonado en 1853. Pío Baroja, entre otros, escribió sobre los descubrimientos de este sitio ${ }^{10}$. $\mathrm{Y}$ había además diversos hallazgos en toda la península que relacionaban a las primitivas tribus ibéricas con las antiguas culturas: egipcia, fenicia, romana, griega ${ }^{11}$.

La moda arqueológica se propagó al arte, a la escultura, a la literatura. Citemos por ejemplo, en la Exposición de Bellas Artes de Madrid en 1881, el cuadro del sevillano Mattoni Las termas de Caracalla, y la Cleopatra de Juan de Lemus, así como la escultura de Francisco Font El enigma de Tebas ${ }^{12}$. En la arquitectura fue popular el estilo neoegipcio, representado por personalidades como el catalán Fontseré, quien en años anteriores se había apegado a la inspiración griega, pero después adoptó características de un mecanicismo egiptizante. Vilaseca fue otro arquitecto que se especializó en motivos griegos y egipcios, complaciéndose en la policromía. Podemos ver un ejemplo en la Academia de Ciencias de la Rambla, erigida en 1883, y en el Panteón Batlló de Barcelona, decorado con cariátides de indumentaria egipcia y rostro helénico.

9 Memorias sobre las notables excavaciones hechas en el Cerro de los Santos publicadas por los PP Escolapios de Yecla, Madrid, 1871. Folleto de 71 páginas debido seguramente a la pluma de Carlos Lasalde. Sobre la polémica sobre estas estatuas véase nuestro libro de próxima aparición en Taurus, El sendero del tigre. Exotismo en la literatura española de fines del siglo $X I X$.

10 Pío Baroja, «Numancia y Soria», El Imparcial (12 junio 1902), 3 y también véase José Ramón Mélida, Excavaciones de Numancia, Madrid, Tipografía de la Revista de Archivos, Bibliotecas y Museos, 1908 y Adolf Schulten, Numancia, Eine Topographische Historische Untersuchung, Berlín, Weidmannsche Buchhandlung, 1905.

11 Véase por ejemplo, M. R. Berlanza, «Descubrimientos arqueológicos de Tajo Montero", Revista de Archivos Bibliotecas y Museos, VI, N. ${ }^{\circ} 435$ (abril y mayo 1902), 328-9; Francisco Codera, «El desarrollo de los estudios arqueológicos en España», Revista de Arqueología Española (Madrid), N. ${ }^{\circ}$ (enero 1880), 14-15; Jorge Bonsor, «Los pueblos antiguos del Guadalquivir», Revista de Archivos, Bibliotecas y Museos, V, N. ${ }^{\circ} 12$ (diciembre 1901), 837-57.

12 Véase Ramón Casellas, "Tercera Exposición General de Bellas Artes», La Vanguardia, XVI, N. ${ }^{\circ} 4654$ (22 abril 1896), 4,5,6. También, «Cleo», La Ilustración Española y Americana XXV, N. ${ }^{\circ} 22$ (15 junio 1881), 387; «Exposición de Bellas Artes», ibíd; N. ${ }^{\circ} 23$ (22 junio 1881), 403-7. 
En lo que respecta a la literatura, se sueña con una reconciliación con la ciencia, y es la arqueología la que proporciona al escritor el más perfecto modelo de cuidadoso detallismo. A ello se une la influencia parnasiana, y sobre todo, la del naturalismo. La influencia de la ciencia en este movimiento no consiste tan sólo en llenar la obra literaria con descripciones de enfermedades, escenas clínicas o de laboratorio, eso es el menor y más superficial efecto ejercido por la ciencia en la literatura. Los temas elegidos son más interesantes y reveladores. Aún más interesante es la forma en que se tratan esos temas. Los románticos ya se habían dado cuenta de que el arte clásico se moría de abstracción, y de que el color local que ellos amaban era el principal procedimiento para conseguir la sensación de vida, haciéndola más concreta y precisa en su evocación de la realidad. Victor Hugo había exaltado la localité exacte, pero a pesar de estas ideas, aquella generación, y Hugo el primero, había mostrado una preocupación relativamente débil por la veracidad de sus localizaciones. Su intento no era el representar las cosas con la exactitud de una época y un medio determinado, sino únicamente dar más vida y apariencia de realidad a sus figuras. Tan sólo querían formar en torno a ellas un conjunto armonioso y exótico.

Sin embargo, a medida que se acerca el fin de siglo el trato con historiadores y arqueólogos y el estudio de estas ciencias enseñaron a los autores, y también el público, a mostrarse más exigentes. El color romántico no bastó. Se pidieron investigaciones serias, accesorios auténticos, descripciones precisas de objetos, sitios, indumentarias. Se llegó a un punto en que unas cuantas acotaciones no bastaban para evocar una antigüedad de oropel ante la mirada ingenua del lector. Se impuso así a la imaginación el control de la ciencia, la documentación a la riqueza de imágenes.

En el prólogo a su novela arqueológica Salomón ${ }^{13}$, publicada en 1884, José Ramón Mélida explica la transformación de la novela histórica desde Walter Scott hasta Bulwer Litton y Jorge Ebers ${ }^{14}$. La evolución es consecuencia lógica de la que ha sufrido la historia, «que antes se redactaba como un acercamiento literario y político, con arreglo

13 José Ramón Mélida, Salomón, Rey de Israel, Leyenda Bíblica, Barcelona, Tipografía Sucesores de Rivadeneira, 1884.

14 La popular novela de Ebers, La hija del rey de Egipto, llegó a su quinta edición española en 1882, Barcelona, Biblioteca Arte y Letras, hermoso libro con grabados a pluma de Apelles Mestres y acuarelas de Arturo Mélida el arquitecto. 
a las referencias de los autores antiguos, y ha sido renovada por la arqueología, que nos ha puesto en comunicación directa con el mundo antiguo». Así la novela, apartándose de los pastiches, ficciones creadas por el pseudorromanticismo, pide hoy «la imitación fiel de la realidad de la vida, y el novelista se preocupa de las circunstancias con que se desarrollan las pasiones de los hombres contemporáneos del medio en que se vive y del ambiente moral que se respira. En una palabra, la historia y la novela buscan la verdad».

Estas palabras exponen un credo estético, La descripción de costumbres, medios, religiones, filosofías y sociedades, usos cotidianos, son lo que forma y determina la escritura. ¿Es esta reconstrucción científicamente exacta? No se trata aquí de verificar el valor erudito de las obras, ni de ver si en su avidez por el documento raro y sugestivo los escritores pesaron suficientementé la veracidad de sus fuentes. Basta reconocer que tenían la voluntad de ser exactos como parte de una meta estética.

No está de más el recordar aquí las investigaciones minuciosas que hicieron Flaubert y Gautier para sus obras de tema arqueológico. Sus pasos fueron modelo para los escritores españoles. José Ramón Mélida, para su relato sobre Salomón, ha seguido las investigaciones sobre la Biblia, estudios como La Bible et ses découvertes modernes en Palestine, en Egypte et en Assirie de M. Vigouroux ${ }^{15}$. Se basa también en los estudios arqueológicos de Perrot, Chiping y Lenormant. A este volumen añade un apeńdice con notas para la comprensión bíblica y arqueológica del relato.

Mélida fue el autor de una novela aún más ambiciosa, localizada en el Egipto faraónico y publicada en 1880 , El sortilegio de Karnak ${ }^{16}$. Declara haberse inspirado para ella en un ostracón formado de un guijarro, con cinco líneas de escritura hierática, que se encuentra en la colección de manuscritos egipcios del Louvre. Incluye en esas páginas abundantes y eruditas notas sobre los descubrimientos arqueológicos egipcios, que le permiten, como conocedor erudito de esa civilización, el reconstruirla primero, y el hacerla vivir después. Se adiciona a la novela un índice bibliográico de obras consultadas, que van desde Heródoto

15 París, Berche et Tralin, 1879, 4 vols.

16 Novela escrita por José Ramón Mélida e Ignacio López, El sortilegio de Karnak, Novela arqueológica, Madrid, Medina, 1880. 
hasta los estudios especializados de Birch, los catálogos de Pierret y los descubrimientos de Champollion y Mariette Bey.

La misma subordinación del autor a la fuente erudita la encontramos en Sónnica la cortesana, novela de Blasco Ibáñez que aparece en Madrid en 1901. El autor explicará en un prólogo posterior a esta fecha las razones que le impulsaron a escribirla ${ }^{17}$. Comenta la popularidad que por entonces tenían esos temas y el éxito de obras como Quo Vadis de Sienkiewickz o la Afrodita de Pierre Louÿs ${ }^{18}$. Pero indica con orgullo sus fuentes originales: «un poema sobre la segunda guerra púnica del poeta latino Silvio Itálico, autor romano del principio de la decadencia, nacido en España».

No se trataba tan sólo de la búsqueda de fuentes. Todas esas obras, además, se organizan a base de la adquisición sistemática de un material especializado que forma una especie de armazón científico de la obra literaria. De esta erudición brota el defecto principal de estas producciones. Casi siempre, la documentación, demasidado rica, aplasta el libro. Ya lo había notado Flaubert al comentar su Salambó.

El exotismo de esas obras preconiza el conformarse a la realidad de una época. Se basa en lograr la reconstrucción de un pasado visto como una especie de libro de imágenes, entre las cuales se aprecian particularmente las que dan noción de exotismo y color local como parte de la dramatización de la historia. Se prodigan las escenas coloristas, fiestas, banquetes, orgías, torneos, batallas, presentados con el intento de parecer narradas por algún espectador contemporáneo a la acción. Se prefieren las escenas de grandes multitudes, que en algún momento explican o determinan la historia.

Pero hay que hacer notar también en este tipo de literatura el descubrimiento de la importancia y significación del detalle verídico concreto. Respondiendo a los deseos del lector moderno, sediento de datos sobre las vidas privadas, buscan una precisión minuciosa en los acontecimientos de la vida cotidiana, en el medio ambiente, en la sociedad del personaje. Interesan asimismo los documentos que conciernen a los he-

17 Prólogo en la edición (Valencia, Prometeo, 1923). Citaremos por la edición de esta novela en Obras Completas, Madrid, Aguilar, 1969.

18 Sobre el éxito de Quo Vadis en España véase nuestro libro de próxima aparición, El sendero del tigre. 
chos menudos. Por ejemplo, se da noticia en una revista española ${ }^{19} \mathrm{de}$ la traducción de unos manuscritos egipcios que conciernen a la vida pública y privada, Recibos librados al fisco por el pago devengado por la cerveza, una carta de un labrador al jefe militar participándole que su hijo se presentara al reclutamiento, etc.

Opina Mélida que ese tipo de literatura, fiel a la meta de deleitar enseñando, encuentra poderosa ayuda en la arqueología, que ha desenterrado las ruinas de los antiguos templos y palacios, explorando tumbas, examinando símbolos e inscripciones, estudiando los caracteres distintos de las obras de arte, y ha puesto de manifiesto la antigüedad: «Memfis, Tebas, Nínive, Jerusalén, Persépolis, Troya, Atenas, Roma, Pompeya son hoy tan conocidas como las grandes capitales del mundo moderno. Pero esas célebres ciudades parecen a nuestros ojos cual vastas necrópolis que, en efecto, son montones de ruinas del pasado, entre las que sólo encontramos las momias y la ceniza de los hombres antiguos». La misión de la novela histórica es «galvanizar esos restos fúnebres, hacerlos hablar, pensar, sentir, hacerlos vivir aquella vida de un tiempo, con sus creencias y leyes, con sus costumbres y modales, en la lucha constante de sus preocupaciones y pasiones, hacernos respirar el ambiente moral de su tiempo, y agitarse en el interior de sus moradas, en los templos de sus dioses, en las calles y lugares públicos de sus ciudades» ${ }^{20}$.

Los escritores españoles notan hechos pequeños, pero expresivos para la evocación de la época por la relación precisa de las modas, los gestos, los usos. Sabían que la resurrección interesante no puede obtenerse más que por la reconstitución exacta del decorado, de los usos de esa vida. Se describen, por ejemplo, ciertas comidas:

Los griegos comían caracoles nadando en salsa de azafrán. Las sardinas frescas del golfo aparecian en rueda sobre los platos, festoneadas de hojas de laurel, y las coronas de pájaros eran servidas cubiertas de salsa verde. Los pastores iberos se contentaban con peces secos y queso duro; los romanos y galos devoraban grandes trozos de cordero chorreando sangre. Las anguilas de los lagos de los puertos eran presentadas con adornos de huevos cocidos, y todos esos platos y otros más iban cargados de sal, de pimienta, de hierbas de color acre, a las cuales se atribuían las más extrañas cualidades ${ }^{21}$.

19 Juan Buscón, «Busca buscando», La Vanguardia, XVII, N. ${ }^{\circ} 5113$ (28 julio 1897), 1.

20 Prólogo a Salomón Rey de Israel, 5.

21 Sónnica la cortesana, 696. 
En El misteri del blat Victor Oliva detalla las actividades de la cosecha hace siglos, al borde del Nilo ${ }^{22}$, y El sortilegio de Karnak el despertar de una ciudad en el antiguo Egipto, como pudiera acontecer en una de la época moderna, con las mismas actividades, las mismas preocupaciones cotidianas: «El luminoso Ra se elevaba en el horizonte [...] Las terrazas de los templos, las techumbres de los palacios, los cobertizos de las humildes moradas y los obeliscos [...] destacándose sobre las blanquecinas masas de la cordillera líbica». El alfarero agita su rueda con celeridad, los esclavos constructores apilan la piedra, los segadores disponen la hoz para la cosecha. Asimismo, en La Voluntad el padre Lasalde y Azorín señalan la similaridad del atuendo de las estatuas del Cerro de los Santos con el de las campesinas yeclanas; y don Adolfo Rivadeneyra, en su hermosa crónica sobre su viaje al interior de Persia $^{23}$, cree ver en los habitantes del Irán los mismos gestos, los mismos usos, las mismas costumbres de los aqueménidas de la comarca persepolitana.

Sónnica la cortesana acontece en Sagunto en el año 200 y tantos A. C. Al comenzar el relato, la célebre ciudad, Zacinto, aliada de Roma, hállase en el apogeo de su prosperidad. Poco tardará en entrar en una guerra contra Aníbal, donde quedará destruida. El personaje principal es Sónnica, cortesana tan hermosa como Friné y tan maestra como Thais en el arte de amar. Intercalados con la acción histórica, se tiene ocasión de narrar sus amores y sus celos, y cómo se convierte en la heroíca defensora de la infortunada ciudad.

En esta novela como en otras de este tipo, por ejemplo Thais se engalana de Luis de Terán ${ }^{24}$, el autor se vuelve particularmente concienzudo en los detalles de la moda femenina, que se vuelve trabajo de crítico de arte y de historiador. Blasco Ibáñez pasa varias páginas en describir el arreglo de la cortesana ${ }^{25}$. Una esclava le alisa el cabello con bellos peines de púas de marfil cincelado. Una pátera de bronce contiene la harina de habas para conservar tersa y tirante la piel de las meji-

22

23 de Aribau, 1880,3 vols. Véase nuestra edición de esta obra próxima a aparecer en, Ediciones del Serbal, Barcelona.

24 Helios, IX (1903), sin paginar.

25 Sónnica la cortesana, 725-7. 
llas, los pechos, el vientre. Usa el dropax, pasta depilatoria compuesta de vinagre y tierra de Chipre. Un ánfora rematada por un pico contiene una disolución de azafrán y goma de Arabia, que con el polvo de oro sirve para teñir el cabello. Primorosos frascos contienen perfumes y aceites traídos por las caravanas de Asia. Se pinta el rostro de blanco y se le aplica el kohol, vendido por los mercaderes egipcios a precios fabulosos, y el antimonio que aviva la mirada, en las mejillas el carmín egipcio, sacado de los excrementos de los cocodrilos. Y junto a la moda está el lugar concedido al mobiliario, tan importante como la historia, y para cuya descripción se ha hecho necesaria una larga lista de estudios.

Estos objetos y actos son siempre vistos como artísticos, de manera que la antigüedad resucitada en sus mínimos detalles se presenta como una forma de arte más compleja. Se incorpora así la belleza a cada gesto, a cada utensilio, a cada prenda de ropa, y se responde con arte al mundo venal contemporáneo.

Todo ello apunta a la sinceridad arqueológica del fin de siglo; asimismo, aquella aptitud para evocar colores, el movimiento, los detalles cotidianos, preservaba a las obras de su abstracción. El ruido de las querellas en la plaza pública y las disputas de los moralistas podían esfumarse en el pasado perdido, no así el sonido de las flautas y los cantos del pueblo, la visión tumultuosa de ceremonias y cortejos, la familiaridad de las escenas privadas.

Veamos ahora algunas de las civilizaciones arqueológicas que interesaban. Llamaban la atención Asiria y Caldea, por sus dioses monstruosos, su mitología bárbara y grandiosa compuesta por dioses de nombre ferozmente extraño, atractivos especiales para el fin de siglo, cansado por el aburguesamiento del cristianismo. Egipto se popularizó por su cercanía a los secretos de ultratumba, por su contacto con un mundo primordial revelado en escrituras secretas y sagradas. Seducían sus misterios, deducidos de la arqueología, de la iconografía de monumentos auténticos, de los descubrimientos lingüísticos. Los jeroglíficos fascinaban como modo de expresión, pero también porque se veía en ellos la transmisión de un inmenso repertorio de simbolismo extravagante, bestiario fabuloso con sus' extrañas uniones de cuerpos y objetos. En la novela Morsamor de Valera, el interés del padre Ambrosio por el hermetismo es significativo; muestra su aspiración por una revelación primordial que incluya no sólo a Moisés y la cábala, sino también a Pla- 
tón, las religiones misteriosas de India, Egipto y Persia, y revela su aspiración por una religión universalista, transhistórica, mítica ${ }^{24}$.

Desde luego, estaba también el gusto por las civilizaciones en decadencia. El fin de siglo, que no dejaba de advertir admoniciones apocalípticas, se identificaba con ellas. Pompeyo Gener comenta el momento cuando «Palas Atenea, Diki y el propio Zeus palidecen y se esfuman al entrar en escena los dos hijos del Asia, dioses de mozos y de martirio, de expiación y de orgía ${ }^{27}$. Discute la época neroniana, cuando las basílicas, los baños, los plátanos del frontón trasmiten las cadencias de los escritores que allí acuden en togas de púrpura, los cabellos rizados, coronados de flores, llenos de perfume. A este punto de vista se debe la popularidad de que gozaron en España libros como Grandeza y decadencia de Roma de Ferrero, La muerte de los dioses de Merykowsku, y sobre todo el tan leído Quo Vadis ${ }^{28}$ de Sienkiewickz, en el que se encontraba, bajo la cobertura neroniana, la belleza plástica del tema, vivacidad de colorido, amplitud y majestad de conjuntos, pero también la fascinación por las orgías romanas, por el espectáculo de las vírgenes ofrecidas a los leones. La Pardo Bazán no dudó en afirmar que en este libro el autor se servía de procedimientos naturalistas para brindar a «la imaginación más gastada cuadros de orgías, de sangre, de torturas, haciendo competencia con El jardín de los suplicios» ${ }^{29}$. Un festín romano de Emilio Castelar ${ }^{30}$ describe esclavas con transparentes túnicas, doncellas coronadas de azafrán, niños casi desnudos que ahuyentan las moscas con ramas de mirto, efebos griegos. Forman parte de un cuadro casi arquetípico. Después de la orgía, los cuerpos extendidos entre cojines y mármoles, se dormita esperando el golpe de gracia de los bárbaros que ya golpean a la puerta y cuya brutalidad se opone al hiperrefinamiento de los romanos.

Véase nuestro artículo, «Morsamor; Un viaje de iniciación hacia la India», Hispanic Review, 53, N. ${ }^{\circ} 2$ (Spring 1985), 181-199.

Pompeu Gener, «L'antich teatre, III, Euripides», Joventut, III, N. ${ }^{\circ} 130$ (7 agosto 1902), 528-30.

Pompeu Gener, «La literatura a Roma, III, La literatura baix Neron», ibíd, III; N. ${ }^{\circ} 146$ (27 noviembre 1902), 766-7.

Emilia Pardo Bazán, «Literatura extranjera. El autor de moda. Enrique Sienkievicz», La Lectura, febrero 1901, 34-46.

La Ilustración Española y Americana, XXVI,N. ${ }^{\circ} 18$ (15 mayo 1882), 367. 
También estaba la atracción por Grecia, y no nos referimos a la clásica, sino a una Grecia teñida de erotismo, que descubría un paganismo exacerbado. La resurrección en el fin de siglo fue la de una Grecia no apolínea sino dionisíaca. Ya no era la vieja tierra clásica, empolvada, abrumada de glosas, sino una región joven, de luz y sol, de efectos violentos y exuberantes.

Se ha dado demasiada importancia a aquel verso de Darío, «amo más la Grecia de la Francia», y comentado demasiado su atracción por una Grecia afrancesada. Lo que Darío, como los demás modernistas, prefiere, es la Grecia de ninfas y sátiros, seres ejemplares, portadores de una vitalidad y sensualidad desenfrenadas. Dentro de este espíritu Mélida reconoce el valor de una escultura en bronce ${ }^{31}$, un asno báquico que presenta el elemento dionisíaco. El carácter greco-arcaico se puede también ver en la arquitectura. En la Casa Calvet de Gaudí (1891-1900) se prodigan las columnas salomónicas, los gabletes mixtilíneos, las columnas de nudos y el aparejo almohadillado de tal modo que, si se ha insistido suficientemente en el barroquismo de esta casa, ha pasado casi inadvertida la inclinación greco-arcaica de los grandes capiteles jónicos y los adornos metálicos con volutas simétricas, como el techo de ascensor, que parece una égida de Palas y muestra la profunda fe mediterraneísta de Gaudí.

Pompeyo Gener, en una serie de artículos que escribió para la revista Juventut sobre el teatro griego, alaba a Esquilo: en su teatro es donde «se forja el alma del hombre a golpes de martillo. Su teatro es de piedra y el cielo es su bóveda. No necesita luz artificial pues lo ilumina el día, la decoración de la naturaleza» ${ }^{32}$.

Los personajes y seres mitológicos que se aprecian son aquellos que seducen por su fuerza y vitalidad, faunos y náyades, símbolos de la lujuria; la Afrodita del poema, saliendo del mar «tota plena de lascivia y d'amor» ${ }^{33}$. Fascinan los centauros que intentaron raptar a las mujeres de los lápitas, mitad hombres, mitad bestias; la sirena, símbolo de

31 José Ramón Mélida, «La colección de bronces antiguos», Revista de Archivos, Bibliotecas y Museos, IV, N. ${ }^{\circ} 8-9$ (agosto-septiembre 1900), 541-46.

32 Pompeu Gener, «L'Antich teatre grech, I, Schilos», Juventut, N. ${ }^{\circ} 129$ (31 julio 1902), 493-4.

33 Joan Verges y Bars, «Afrodita», ibíd; VI, N. ${ }^{\circ} 265$ (9 marzo 1905), 160. 
la lujuria; la esfinge que figura la voluptuosidad y sus peligros, con rostro y pecho de mujer y cuerpo de león devorador.

Esa antigüedad tenía otro atractivo. Era un santuario poco accesible al burgués. Se reproducían en las obras los nombres griegos exactos para romper las asociaciones enojosas con los nombres latinos y las adaptaciones mitológicas de un arte demasiado afrancesado, incompatible con el carácter tan precioso de exotismo que se quería restituir.

En el exotismo arqueológico también puede verse la gran influencia que hay entre las artes plásticas y la literatura. Antes había sucedido lo contrario, la literatura había invadido y hasta dominado las artes, pero ahora la plástica toma su revancha. En el estilo, el epíteto exotista y descriptivo y el nombre propio y pintoresco disputan el lugar que antes había tenido lo moral. Se logra una literatura de imágenes: "La noche inundaba el Nilo con su densa oscuridad, esmaltada por un sin fin de estrellas cien veces más brillantes que las joyas del Faraón y las esmeraldas de Ollaki» ${ }^{34}$. La descripción se encamina a la representación material, hasta el punto de que el adagio Ut pictura poesis jamás ha sido más justo. Los esmaltes, camafeos, cariátides, festones, astrágalos abundan. El monumento domina en la literatura funcionando como una especie de lenguaje: «Sobre el poniente se confundían las macizas moles de los templos en una masa confusa sobre las que surgían, cual brazos implorantes, las agujas esbeltas de los obeliscos [ ... ]. Frente a casa de Thamar un último rayo de sol [ ... ] ensangrentaba el muro frontero roído por los jeroglíficos» ${ }^{35}$.

Los personajes de estas obras tienden a ser convertidos en obra de arte, así como las localizaciones. Egipto, «con sus animales divinizados, con sus rígidos faraones cubiertos de oro, con sus anchas columnas de capiteles de flor de loto, con el sagrado Nilo inmóvil como si sus ondas fuesen de un metal fulgurante, con sus momias cubiertas de betún y esmaltes» ${ }^{36}$. Una mujer sentada y vestida de túnica blanca,

34 El sortilegio de Karnak, 149.

35 Mauricio López Roberts, «La tristeza de Thamar», Blanco y Negro, XIV, N. 690 (23 julio 1904), sin paginar.

36 Isaac Muñoz, Ambigua y cruel, Madrid, Imprenta Helénica, 1912. 
«aparecía cual busto de marfil»» ${ }^{37}$. Otra parecía «una Isis esculpida en marfil», y su varonil acompañante «como el Horus de basalto rojo» ${ }^{38}$.

El color también tiene predominio. Ya no se trata de una antigüedad inmóvil y descolorida, de piedra, de mármol o de yeso, que evocan las estatuas prisioneras, alineadas administrativamente a la sombra de los museos. El colorido estalla desbordante en procesiones, ceremonias y personas. Un vistọso desfile deja ver arqueros con enormes carcajes de madera oscura y flechas de plumas multicolores. Los camellos los siguen, con grandes cestos cubiertos de ricos paños verdes. Continúan los esclavos, vestidos de amarillo, tras ellos los tigres, de arrogante aspecto, y panteras negras rozando el suelo con sus colas. Jirafas de altos cuellos moteados y elefantes con quitasoles de colores vivos y engalanados con gualdrapas, «en que el tono purpúreo hacía resaltar los geométricos adornos bordados: azules, verdosos, amarillentos, y negros, así como el oro y las pedrerías» ${ }^{39}$.

En esa antigüedad revivida el color estalla y desborda, la casta palidez y los contornos tranquilos de los mármoles no bastan. Sus paisajes se extienden bajo el firmamento estrellado. La desnudez de las carnes de las estatuas se vena de azul; los edificios se ven de color ladrillo con tonos de betún y tinta. Por esos años Gaudí subrayaba el efecto policromado de la arquitectura. El color era para él la manifestación visible de la vida. Insistía en que los egipcios y los griegos policromaban sus templos y estatuas a pesar del rico mármol que usaban. Así entendida e interpretada, la antigüedad ofrecía al artista, al escritor, al arquitecto, algo que faltaba en el mundo moderno, monótono y frío: la extravagancia, la variedad, el exotismo.

37 El sortilegio de Karnak, 168.

38 Ibíd; 154.

39 Ibíd; 21-22. 